IZA DP No. 7994

Crowdfunding, Cascades and Informed Investors

Simon C. Parker

February 2014 


\title{
Crowdfunding, Cascades and Informed Investors
}

\author{
Simon C. Parker \\ Western University, Canada \\ and IZA
}

\section{Discussion Paper No. 7994 \\ February 2014}

\author{
IZA \\ P.O. Box 7240 \\ 53072 Bonn \\ Germany \\ Phone: +49-228-3894-0 \\ Fax: +49-228-3894-180 \\ E-mail: iza@iza.org
}

Any opinions expressed here are those of the author(s) and not those of IZA. Research published in this series may include views on policy, but the institute itself takes no institutional policy positions. The IZA research network is committed to the IZA Guiding Principles of Research Integrity.

The Institute for the Study of Labor (IZA) in Bonn is a local and virtual international research center and a place of communication between science, politics and business. IZA is an independent nonprofit organization supported by Deutsche Post Foundation. The center is associated with the University of Bonn and offers a stimulating research environment through its international network, workshops and conferences, data service, project support, research visits and doctoral program. IZA engages in (i) original and internationally competitive research in all fields of labor economics, (ii) development of policy concepts, and (iii) dissemination of research results and concepts to the interested public.

IZA Discussion Papers often represent preliminary work and are circulated to encourage discussion. Citation of such a paper should account for its provisional character. A revised version may be available directly from the author. 
IZA Discussion Paper No. 7994

February 2014

\section{ABSTRACT}

\section{Crowdfunding, Cascades and Informed Investors}

Do higher proportions of (a) informed investors and (b) high-quality projects increase the number of good projects that are ultimately financed via crowdfunding? A simple model and simulation reveals the answers to both questions to be: 'not necessarily'.

JEL Classification: L26, C63, G23

Keywords: crowdfunding, new ventures, entrepreneurial finance, startups

Corresponding author:

Simon C. Parker

\#2253 Ivey Business School

Western University

1255 Western Road

N6G ON1 London, ON

Canada

E-mail: sparker@ivey.uwo.ca 
Crowdfunding platforms enable members of the public to make small investments in ventures pitched by entrepreneurs (Agrawal et al, 2013). In the United States, equity crowdfunding was legalized in April 2012 when President Obama signed into law the JOBS Act (Stemler, 2013): this permits investors to take small shareholdings in new startups. Research on crowdfunding is beginning to emerge, though it mostly focuses on donation-based funding (Burtsch et al, 2013; Mollick, 2014).

Several studies show that accumulated capital invested in projects serves as an informative but noisy signal of project quality (Agrawal et al, 2011; Burtsch et al, 2013) and can cause information cascades to form. Yet we still know little about whether cascades have positive or negative effects on crowdfunding investments, especially when multiple projects are competing simultaneously for funding. This paper sheds light on this issue in a simple setting that incorporates prominent features of investment-based crowdfunding platforms. Some projects are of good underlying quality while others are not: investors face asymmetric information about the identity of projects. Some investors have informative but imperfect signals of project quality while others do not; but everyone invests limited funds in one of several competing projects. I find, unexpectedly, that higher proportions of informed investors do not always lead to more good projects being funded; and a higher proportion of bad projects in the pool can paradoxically increase the number of good projects that end up funded. These findings may be of practical interest to entrepreneurs, investors, and crowdfunding platforms.

\section{The Model}

There are $n$ investors, where $n$ is a positive, finite integer. I assume that $n$ is unknown, which seems realistic given the geographically dispersed, online setting of crowdfunding (Agrawal et al, 2011).n is taken to be large enough that each individual investor regards themselves as atomistic, i.e. they do not make investment decisions in order to influence investors who invest after them (Bikhchandani et al, 1992). As in Welch (1992), resource scarcity is modeled by having all investors (who arrive in a random sequence) commit exactly one dollar to one and only one project of their choosing. The crowdfunding platform presents an integer number $m$ projects to choose from: all of these available projects start and end at the same time. Of these projects, an integer number $l$ (where $l<m$ ) are classed as 'good'; the identities of good projects are unknown to investors. 
If they receive funding, a good project yields a positive rate of return; the remaining $m-l$ projects are 'bad', yielding a lower (possibly negative) rate of return. Consistent with the design of most crowdfunding platforms, there is a 'provision point mechanism', whereby projects are only funded if a publicly-declared funding threshold is reached within the funding window, $n$. Since all investors invest one dollar, the threshold can be parameterized as the need for $k$ investors to invest in a project, where $k$ is treated as exogenous. ${ }^{1}$ If projects are not funded, investors get just their stake back, i.e. a zero rate of return.

A proportion $\theta$ (where $0<\theta<1$ ) of investors are 'informed', receiving an informative signal about one of the $l$ good projects. A signal correctly identifies a project as good with probability $\zeta$ (where $0<\zeta<1$ ). For the signal to be useful, $\zeta>\frac{l}{m}$. The remaining proportion $1-\theta$ of investors is uninformed, receiving no signal. Although $\theta$ and $\zeta$ are public knowledge, receipt of a signal is private information. Consistent with the design of most crowdfunding sites, however, everyone can observe the cumulative amounts invested in each project. The owners of projects know the type of their project but cannot signal this credibly to investors, leading to a pooling equilibrium. To avoid a trivial problem in which all projects can be funded, assume $k m>n$.

Turning to investment decisions, it is always optimal for an uninformed investor to invest in the project with the greatest amount of investment so far, since that project is associated with the greatest expected number of positive, informed signals. An informed investor is also interested in the expected number of such signals, but they also have private information. Suppose they get a signal about project $j$, which has attracted $g^{j}$ dollars so far. The investor wants to know the probability that there were $a$ signals out of the $g^{j}$ possible signals that could have been received, where $a \in\left\{0,1, \ldots, g^{j}\right\}$. Letting $A$ denote the number of signals,

$$
P\left(A=a \mid g^{j}, \theta\right)=\left(\begin{array}{c}
g^{j} \\
a
\end{array}\right) \theta^{a}(1-\theta)^{g^{j}-a} \quad, a=0,1, \ldots, g^{j}
$$

Of course, this is just the density function of the binomial distribution, whose expected value is

$$
E\left(A \mid g^{j}, \theta\right)=g^{j} \theta
$$

\footnotetext{
${ }^{1}$ Some equity-based platforms, such as crowdcube.com, enable entrepreneurs to set a secondary target once the first target is reached, and obtain additional funds. For simplicity, this possibility is not modeled below.
} 
Hence, counting the informed investor's signal, the expected number of signals for project $j$ is $1+g^{j} \theta$.

Index the non- $j$ project with the greatest dollar investment so far by $i$, where $i \neq j$. By the above reasoning, the expected number of good signals for project $i$ is $g^{i} \theta$. Hence an informed investor should use their private information to invest in $j$ as long as

$$
\left(g^{i}-g^{j}\right) \theta \leq 1
$$

If this inequality is reversed, an informed investor should disregard their private information and choose the project with the greatest number of investments: at this juncture they behave like an uninformed investor. An 'information cascade' starts at the point that (1) holds with equality. As previous work has shown, cascades can form for both good and bad projects; and they can be suboptimal, leading to funding of bad projects instead of good ones (Bikhchandani et al, 1992). ${ }^{2}$

\section{Simulation}

The path dependence inherent in the model necessitates a simulation approach. Let $\Psi=$ $(k, l, m, n, \theta, \zeta)$ denote the parameters of the model. The output of interest is the expected number of good projects funded, $\Pi$, for a given $\Psi$. That is because the number of successful projects funded is likely related to the amount of innovation and the creation of economic value. The simulations report $\Pi$ for various values of $\theta \in\{0.01,0.02, \ldots, 0.99\}$ and $l \in\{1,2, \ldots, 9\}$. The value $\zeta=0.92>$ $9 / 10$ ensures that signals are informative; $k=10$; and $n=30 .^{3}$

Investors use the decision rules established in the previous section; when they face more than one equally good option (e.g. as the first investor does if she is uninformed), a random tie-breaker is utilized. For any given $\Psi$, complete investment sequences are repeated 10,000 times to average

\footnotetext{
${ }^{2}$ Note that: (i) the decision rule above does not depend on $\zeta$ because all signals are assumed equally accurate; (ii) $\theta$ was assumed known: greater complexity would arise if investors estimated $\theta$ with heterogeneous prior beliefs; and (iii) $n$ was assumed unknown: the decision rule (1) would have to be modified were $n$ known. Generalizing the model by relaxing these assumptions is a task left to future research.

${ }^{3}$ It might seem that $n=30$ is too small to permit individuals to regard themselves as 'atomistic', as assumed in the model. But as shown below, $k$ and $n$ can be scaled up together without affecting the qualitative results.
} 
over different random investor arrivals, tie breaks, etc. The institutional set-up and investment decisions described in the previous section are coded into an APL program (available on request).

Figure 1 graphs the results: $\theta$ and $l$ appear on the two horizontal axes and $\Pi$ is on the vertical axis. Figure 1 shows that if most investors are informed $(\theta \geq 0.75)$ the $\Pi \sim /$ relationship is inverse- $U$ shaped, with $\Pi$ reaching a maximum at $l=5$. Hence having more good projects in the pool is not necessarily associated with greater funding of good projects. Also, the $\Pi \sim \theta$ relationship is nonlinear, being strictly increasing only for $l \leq 4$, and generally decreasing at higher values of $l$. Hence having a higher proportion of informed investors in the crowdfunding population is not necessarily better, either.

The logic is as follows. When most investors are uninformed, they tend to follow the few informed investors, who predominantly back good projects. But numerous informed investors tend to concentrate funding on only the good projects. That does not spread finite resources $(n=30)$ too thinly as long as $l$ is low; but when $l$ is high, there are too few cascades, which are needed to bring some of them to the funding threshold.

Figure 2 depicts what happens when $n$ is increased to 50 , all else equal. More projects can now be funded: in fact, $47 \%$ of projects (both good and bad) now achieve the threshold (averaged over the entire $l \times \theta$ space of Figure 2) - compared with $25 \%$ for Figure 1 . The non-linearity is less pronounced in Figure 2, as would be expected if more investors can fund projects; but a similar pattern as before is observed for high values of $l$ and $\theta$. It is noteworthy that the UK equity crowdfunding site crowdcube.com reports that only $24 \%$ of its startup pitches end up fully funded (see www.crowdcube.com/infographic).

Figure 3 summarizes the results of quintupling $k$ and $n$, to 50 and 150, respectively. Evidently scaling does not change the main findings. As a further robustness check, the simulation was repeated using $\zeta=0.72$; the results were also qualitatively unchanged (available on request). ${ }^{4}$

\footnotetext{
${ }^{4}$ In all parameterizations, the number of bad projects funded is broadly decreasing in both $\theta$ and $l$.
} 


\section{Conclusion}

This simulation exercise has shown that information cascades can mitigate the problem whereby private information leads investors to spread resources so thinly that few good projects achieve the funding they require. Uninformed investors are the most active promoters of cascades, which can explain why, paradoxically, their presence can sometimes improve the functioning of crowdfunding markets. Similar reasoning applies to the existence of 'bad' projects: although information cascades can result in some of these gaining funding, a pool dominated by too many good projects can again lead to investments in them being spread too thinly. A practical implication is that equity crowdfunding platforms might encounter diminishing returns to any efforts designed to improve the quality of participating projects and investors.

Of course, too many bad projects likely incur resource costs: future research is needed to estimate the balance between good and bad projects and how crowdfunding platforms can strike an optimal balance between them.

\section{References}

Agrawal, A.K., C. Catalini and A. Goldfarb (2011). The geography of crowdfunding, NBER Working Paper No. 16820, Cambridge MA

Agrawal, A.K., C. Catalini and A. Goldfarb (2013). Some simple economics of crowdfunding, NBER Working Paper No. 19133, Cambridge MA

Bikhchandani, S., D. Hirshleifer and I. Welch (1992). A theory of fads, fashion, custom and cultural change as informational cascades, Journal of Political Economy, 100(5): 992-1026.

Burtch, G., A. Ghose and S. Wattal (2013). An empirical examination of the antecedents and consequences of contribution patterns in crowd-funded markets, Working Paper.

Mollick, E. (2014). The dynamics of crowdfunding: an exploratory study, Journal of Business Venturing, 29(1): 1-16.

Stemler, A.R. (2013). The JOBS Act and crowdfunding: harnessing the power - and money - of the masses, Business Horizons, 56: 271-275

Welch, I. (1992). Sequential sales, learning and cascades, Journal of Finance, 47(2): 695-732. 


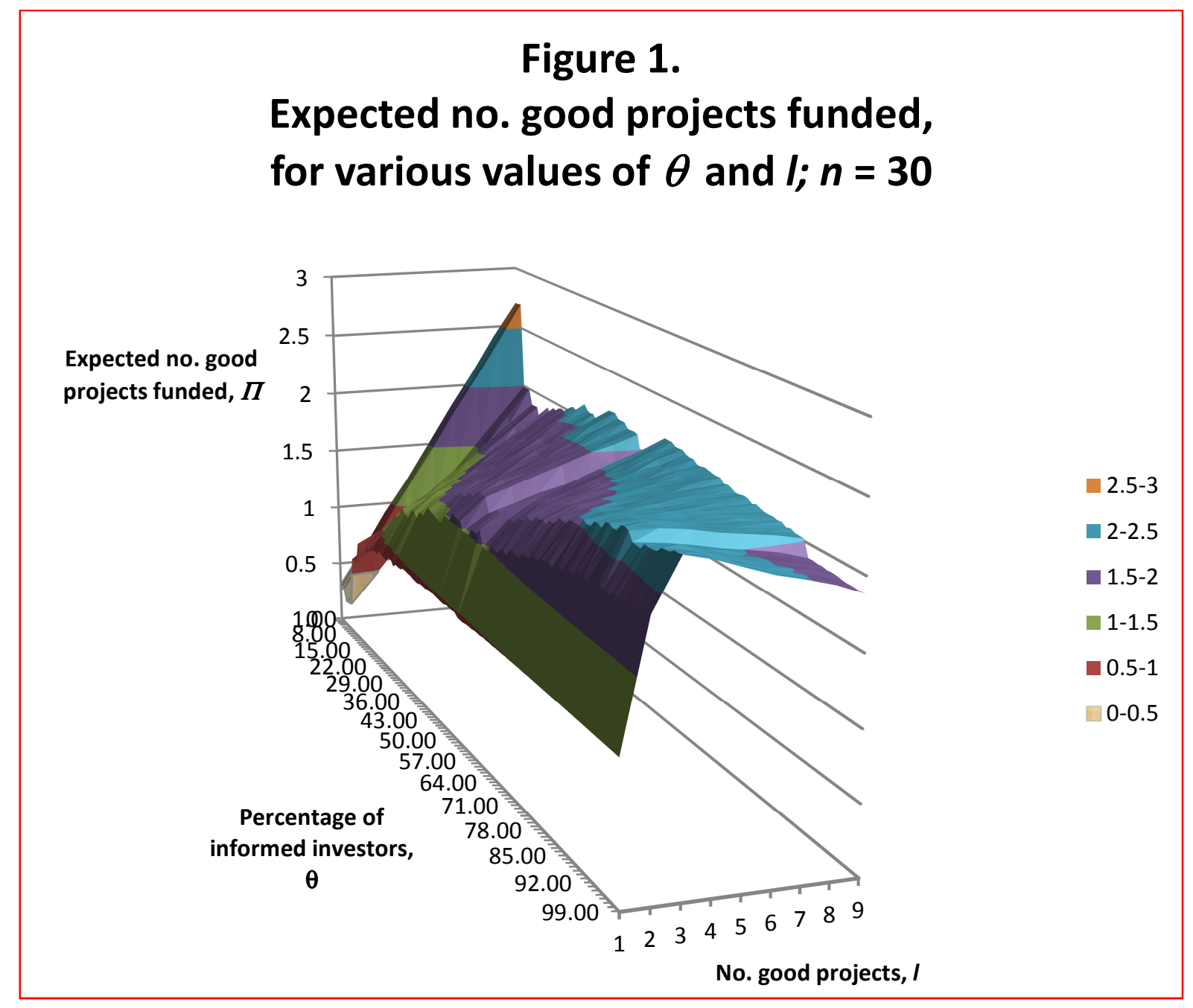

Notes:

$\Psi=(10, l, 10,30, \theta, 0.92)$ 
Figure 2.

Expected no. good projects funded, for various values of $\theta$ and $l ; n=50$

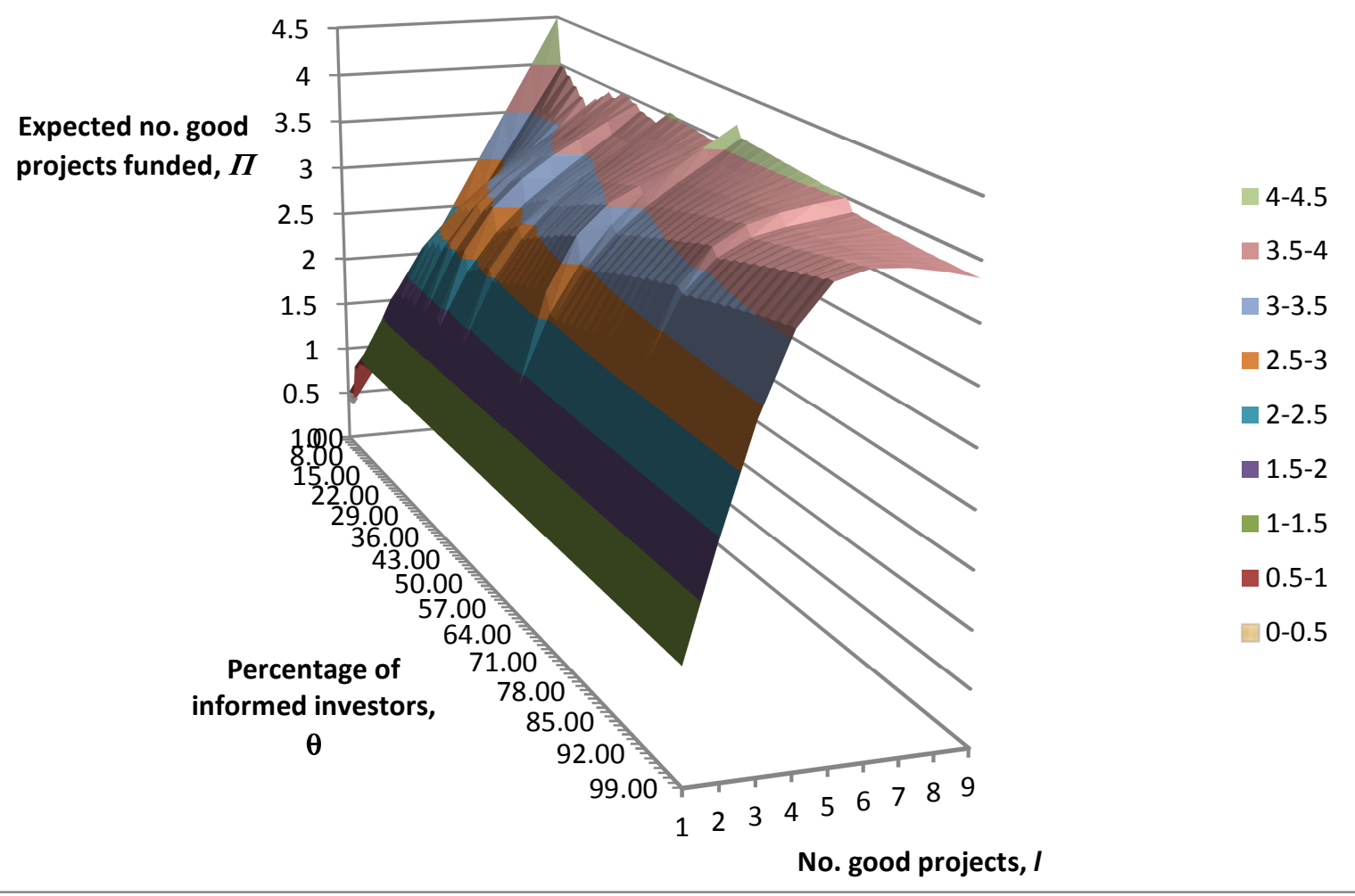

Notes:

$\Psi=(10, l, 10,50, \theta, 0.92)$ 


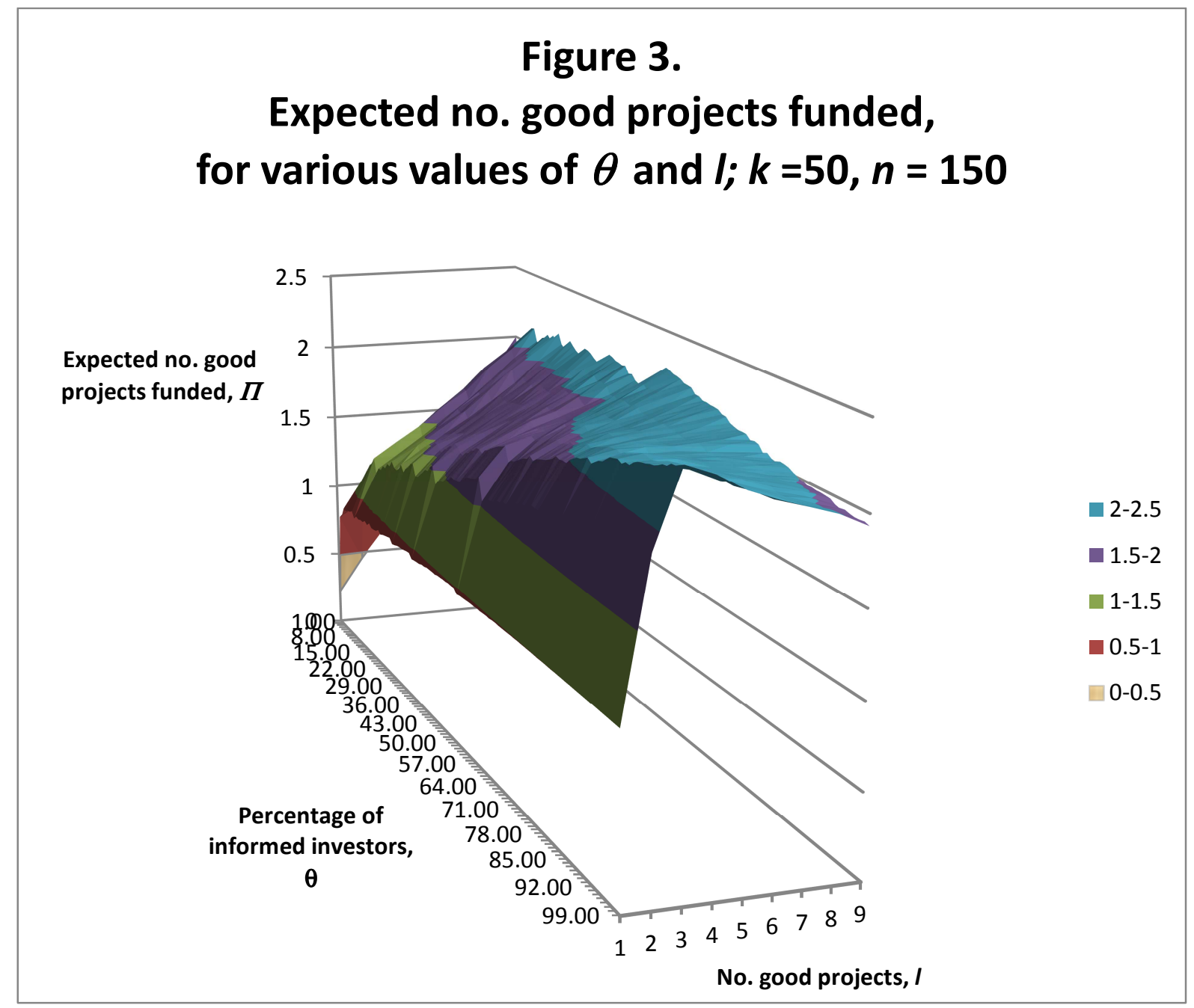

Notes:

$\Psi=(50, l, 10,150, \theta, 0.92)$ 